\title{
GESTÃO PARTICIPATIVA NAS ESCOLAS: CONCEITOS QUE DESAFIAM A PRÁTICA
}

\section{PARTICIPATORY MANAGEMENT IN SCHOOLS: CONCEPTS THAT CHALLENGE PRACTICE}

Recebido em: 20/05/2018. Aceito em: 31/10/2018.

Claudivan Santos Guimarães ${ }^{1}$

\section{RESUMO}

Este artigo é o resultado da pesquisa feita sobre "Gestão Participativa nas Escolas: conceitos que desafiam a prática” e tem como objetivo refletir sobre os conceitos e desafios da gestão participativa nas escolas a partir da revisão bibliográfica de autores como Faria, Lima, Lopes, Mill e outros teóricos que permitem elucidar a referida temática. As etapas dessa pesquisa estão divididas em apresentação dos conceitos de gestão, participação e democracia e reflexão sobre os desafios da gestão participativa. No desenvolvimento do artigo que compreende ao capítulo teórico se faz uma referência entre a relação de participação e democracia, atenuando para a definição de que são conceitos que se entrelaçam, já na composição que trata dos desafios da escola se estabelece que a falta de autonomia das instituições escolares comprometem o exercício de uma gestão democrática nas escolas. Por fim, a pesquisa considera que o modelo participativo é acertado diante de uma sociedade que tem acompanhado os serviços sociais que lhe são oferecidos.

Palavras-chave: Gestão Participativa. Conceitos. Desafios.

\section{ABSTRACT}

This article is the result of research done on "Participatory Management in Schools: concepts that challenge the practice" and aims to reflect on the concepts and challenges of participatory management in schools from the literature review authors like Faria Lima Lopes, Mill and other theorists who allow elucidating the said theme. The steps of this research are divided into presentation of management concepts, democracy and participation and reflection on the challenges of participatory management. In

1 Especialista em Gestão Escolar pela Faculdade Amadeus (FAMA) e graduado em História pela Universidade Federal de Sergipe (UFS).

E-mail: claudivan.guimaraes@hotmail.com 
the development of the article comprising the theoretical chapter becomes a reference relationship between participation and democracy, reducing to define concepts that are interwoven, since the composition to address the challenges of the school is established that the lack of autonomy of educational institutions undertake the exercise of democratic management in schools. Finally, the research finds that the participatory model is hit from a society that has accompanied the social services that are offered.

Keywords: Participatory Management. Concepts. Challenges.

\section{INTRODUÇÃO}

A sociedade contemporânea vivencia um momento na educação que tem exigido cada vez mais a participação social na vida escolar. Este fato tem ocorrido em função da inserção na escola de elementos que provoquem sua autonomia, como é o caso da obrigatoriedade de Conselhos Escolares, um órgão colegiado que democratiza e populariza as decisões tomadas pela comunidade escolar.

Esse exemplo mostra como a participação popular pode ser fundamental na vida escolar, pois descentraliza as relações do gestor e as decisões são tomadas em conjunto, envolvendo a comunidade nos processos de construção do ensino-aprendizagem dos alunos. Esse modelo de gestão participativa contempla os princípios de democracia e de autonomia da escola, propiciando maior abertura da escola para o meio social em que está inserida.

Como consequência desta reflexão surgiu a presente pesquisa intitulada como "Gestão Participativa nas Escolas: conceitos que desafiam a prática" com o objetivo de refletir sobre os conceitos e desafios da gestão participativa nas escolas. As hipóteses eleitas para este estudo foram: Quais os conceitos de gestão, participação e democracia? Qual o modelo de gestão a ser adotado nas escolas? Quais os desafios da gestão participativa na sociedade contemporânea?

Esta reflexão se justifica por entender que a adoção de um modelo de gestão participativa nas escolas facilita a relação com a sociedade e esta com a escola, além de proporcionar maior envolvimento da comunidade nas escolhas e ações a serem desempenhadas pelas instituições.

Com relação aos procedimentos metodológicos, o estudo se constitui de uma pesquisa bibliográfica, a partir da abordagem teórica de autores como Faria, Lima, Lopes, Mill e outros que forneceram abertura para uma discussão coerente. A coleta de dados prestigiou ainda a reflexão a partir da apresentação de princípios da Lei de Diretrizes e Bases da Educação Nacional. O objeto de estudo em questão é a gestão participativa. 
Com isso, os estudos sobre gestão participativa direcionam para a necessidade de autonomia das escolas e definição de uma forma de gestão que aproxime a sociedade do ambiente escolar,

\section{REVISÃO BIBLIOGRÁFICA}

\section{CONCEITUANDO GESTÃO E PARTICIPAÇÃO}

Os termos acima exigem que se façam algumas interrogações antes de dar continuidade a essa reflexão. Qual o conceito de gestão? Quais os modelos de gestão? Qual a relação entre democracia e participação?

O que se verifica a seguir é o resultado da argumentação teórica que permite responder a essas perguntas. Em primeiro lugar, devem-se contemplar os conceitos tanto de gestão como de democracia, pois a participação reside no exercício da democracia.

Nas casas, na empresa, na igreja ou mesmo nas Instituições escolares, é possível verificar a presença de um gestor, de um representante, diretor, um chefe. Bem essas figuras são as responsáveis por dar organicidade ao aparelho social que administram, seja a casa, a igreja ou a escola. Estas pessoas podem ser escolhidas por outra pessoa ou porque sua função social está intimamente ligada a esta tarefa.

A gestão das organizações sociais é antecipada do conceito e função de Estado, que está relacionado a capacidade de organizar os formatos que a sociedade se modela para atender as necessidades das pessoas, neste sentido o conceito de,

\footnotetext{
Estado se constitui e se desenvolve como intérprete dos interesses dominantes (hegemônicos), seja pelo ordenamento jurídico, pela regulação das atividades sociais e políticas, pela transmissão ideológica, seja como garantia da reprodução do modo de produção que lhe confere seus formatos” (Faria, 2009, p. 10)
}

Este conceito se constitui da função de atender as organizações, regulando-as na produção e em suas atividades sociais e políticas. Dentro desse sistema regulatório então nasce a gestão nas organizações, que emana dos princípios do Estado.

A gestão então está relacionada ao conjunto de normas e ou diretrizes e atividades que fazem funcionar as organizações sociais. Gerir de acordo com Wittman (1998) é procurar direcionar as metas e possibilitar a abertura dos caminhos que levarão aos bons desempenhos da organização. Esses caminhos são alargados quando a gestão é compartilhada, mas antes de definir como se dá essa participação vejamos alguns conceitos de gestão educacional, pois este é o objeto de estudo desta pesquisa.

Alguns autores como Lopes (1997) afirmam que as escolas devem estar preparadas no século XXI para uma gestão organizada e cada vez mais complexa, em que seja possível direcionar suas complexidades financeiras, pedagógicas e administrativas. Então na escola a gestão deve estar baseada em modelos que descentralize a função do gestor e possibilite o acesso de mais pessoas na tomada de decisões. 
As decisões quando compartilhadas podem ser melhor aplicadas, embora, aconteça comumente das decisões ficarem centradas apenas na figura do gestor, ou diretor. Sua posição na organização escolar não deve refletir um caráter de arrogância, pois esta característica quando exercida pode dificultar a capacidade de relação com os demais envolvidos na organização escolar.

A reflexão que deve ser feita no conceito de gestão escolar é que mesmo ela acontecendo com a interferência dos representantes do poder, ou seja, do executivo, pode haver na escola a aplicação de modelos de gestão que não centralize esse papel na figura do diretor ou de sua equipe. Observa-se então a significação para modelo de gestão:

\footnotetext{
Um modelo de gestão assim caracterizado e definido assemelha-se a um protótipo e, neste sentido, parece pressupor que a acção organizacional, em cada escola, é exclusivamente orientada por um modelo - é uma réplica, uma imagem reflectida sem distorções assinaláveis ou, no limite, uma fotocópia fiel. As estruturas e as formas encontram-se pré-definidas e estabelecidas, são anteriores à acção organizacional escolar, guiam-na, sendo reproduzidas em conformidade, isto é, sendo actualizadas e concretizadas consoante está formalmente previsto. (Lima, 1999, p. 05)
}

Por esse excerto se define modelo de gestão como uma concepção prévia da imagem a ser aplicada na administração da escola, esta imagem pode ser refletida de um modelo corrente, como é o caso das Secretaria Municipais de Educação, ou autônoma, quando a própria escola produz suas orientações para a gestão.

Não há de acordo com Lima (1999) uma forma ideal para gerir um espaço, pois depende da interferência do meio social e de como esta sociedade ver os comportamentos do gestor diante da tomada de decisões, que podem impulsionar a participação quando não acontecem os resultados esperados.

Na escola podem ser aplicados modelos de gestão de acordo com a realidade social da comunidade a sua volta, geralmente um modelo centralizador, onde o diretor defina todos os procedimentos a serem adotados na escola não resulta numa popularização dos conhecimentos sobre a escola, o que pode acontecer nesse tipo de atitude é uma reação de aversão a figura do gestor.

O que se observa é uma teoria que nem sempre segue o que determina a Lei de Diretrizes e Bases da Educação Nacional - LDBEN, a aplicação do princípio de uma gestão que seja democrática e leve a uma socialização da filosofia da escola e de suas atitudes diante da comunidade. Um modelo de gestão democrática pode levar a aproximação da comunidade na escola, o que por sua vez ajuda na relação da família com a escola. Este modelo está implícito na própria legislação educacional quando no Art. $3^{\circ}$ Inciso VIII da LDB (2007), determina a prática de "gestão democrática do ensino público, na forma desta lei e da legislação dos sistemas de ensino”.

O modelo democrático, determinado pela LDB é acertado quando possibilita que a administração escolar seja pleiteada num conjunto, relacionando as variantes que formam a escola: família, profissionais da educação e estudantes. 
Este formato de gestão escolar é ampliado quando se insere a participação ativa da sociedade nos objetivos e estratégias tomadas pela escola, pois, os pais, alunos, professores e técnicos devem estar inseridos no debate sobre os serviços disponibilizados pela escola.

\section{CONCEITUANDO PARTICIPAÇÃO A PARTIR DE DEMOCRACIA}

Participar da administração escolar é uma atitude democrática, e por isso é necessário se aplicar um breve conceito de democracia para atenuar sobre como esta deve ser organizada e atendida pelas instituições escolares.

O termo democracia sugere a contemplação de uma forma de governo que nasce da vontade popular, ou seja, da real participação da população na escolha e na execução de suas vontades por meio de seu conjunto de leis que são construídas através da sua representação nas Casas de leis. Um conceito menos generalizado para a democracia como forma de governo pode ser destacado através da seguinte citação:

\footnotetext{
Não há dificuldades em mostrar que a forma de governo idealmente melhor é aquela na qual a soberania ou o poder controlador supremo, em último recurso, é conferido ao agregado inteiro da comunidade; onde cada cidadão não tem somente voz no exercício da soberania extrema, mas é chamado, pelo menos ocasionalmente, para realmente atuar no governo através de desempenho pessoal de alguma função pública, local ou geral. (Mill, 2006, p. 54)
}

Certamente, a ideia de Stuart Mill, sobre um modelo de governo que a participação popular de fato seja exercida, provoca então entender que a democracia nasce dessa participação. As pessoas de uma determinada sociedade são parte de um conjunto de escolhas e atitudes, logo sua presença nos momentos de democracia de seus país e de suas organizações é indispensável.

A escola como ente social, tem como responsabilidade aplicar essa forma de gestão em que a população seja ativa participante, mas também influenciar na construção de uma consciência democrática, objetivando o entendimento futuro do que seja democracia e sua importância para a administração não apenas da escola, mas da sociedade como um todo.

Assim como Mill (2006) sugere, pela democracia a sociedade é oportunizada a participar da vida política e social, cujo verbo se confunde com o conceito de democracia apresentado. $\mathrm{O}$ cidadão deve ser levado a se envolver naquilo que lhe é de interesse, pois assim como numa sociedade complexa, na escola as escolhas e ações devem ser compartilhadas.

\section{A PRÁTICA DA GESTÃO PARTICIPATIVA NAS ESCOLAS}

A gestão participativa nas escolas acontece dentro de três dimensões: definição do modelo de gestão, descentralização do poder e envolvimento da sociedade. 
Já foi abordado que as escolas precisam definir o modelo de gestão a ser explorado, pois é através dele que se faz a projeção para as expectativas do futuro escolar, em sentido prático, seria como constituir um projeto pedagógico para a escola e definir objetivos, justificativa, filosofia, hipóteses, cronograma, em fim uma série de etapas que compõe o projeto. A escolha pelo modelo de gestão também funciona neste sentido.

Escolher o modelo de gestão participativa é abraçar as orientações da LDB de 1996 e ainda atender aos princípios constitucionais de democracia, pois o modo de governabilidade no Brasil está calçado nessa base política.

A gestão escolar na sociedade contemporânea demanda além da formação técnica, mas uma boa relação social do gestor com a comunidade escolar, pois as demandas sociais e educacionais têm sido alargadas e os problemas que a escola tem que enfrentar não permite separar a sociedade da escola.

A participação da sociedade na gestão da escola começa com a escolha dos representantes de para a direção das escolas, pois como se trata de um ambiente público a escola deve ter como diretriz os moldes de governabilidade estabelecidos pela Constituição Federal do Brasil, através do voto, de um grupo representativo, de conselhos, ou de toda a comunidade escolar. Esta reflexão pode ser explorada a seguir.

\footnotetext{
"A democratização dos sistemas de ensino e da escola implica aprendizado e vivência do exercício de participação e de tomadas de decisão. Trata-se de um processo a ser construído coletivamente, que considera a especificidade e a possibilidade histórica e cultural de cada sistema de ensino: municipal, distrital, estadual ou federal de cada escola." (Brasil, 2004, p. 25)
}

A democracia na escola, como se ver no fragmento citado deve ser construído paulatinamente, de fato não é do dia para a noite que as escolas estarão adaptadas a uma gestão participativa, mas é por meio da discussão e linear aplicação de uma gestão mais democrática que se poderá contemplar sua abrangência nas escolas públicas.

O envolvimento da população na vida escolar, demanda como foi visto acima, exaustiva participação, sejam em reuniões, eleições, formações, debates, projetos disciplinares e pedagógicos, escolha de representantes, grêmios, em toda forma de relação possível em que subjetivamente haja a necessidade de participação dos membros da comunidade escolar. Por meio do envolvimento é que a sociedade deixará de ser mera ouvidora da escola e sim uma interlocutora de suas ações.

Somado ao que fora dito até aqui sobre participação, carece que os gestores escolares possam abrir espaço para a reflexão das decisões. De fato, aplicar a democracia não é algo fácil, pois envolve muitas opiniões e que nem sempre agradam a pessoa que estar a frente de uma determinada organização, contudo pela democracia na escola, ouvindo e refletindo sobre as vozes da sociedade as decisões certamente estarão sendo descentralizadas e o poder compartilhado.

Descentralizar o poder do gestor na escola é pensar também em qualidade de ensino, pois por meio de uma participação maior da sociedade também se pode avaliar 
os riscos, malefícios e necessidades de um determinado campo do conhecimento, afinal a família estará inserida nesse processo. Percebe-se então que,

Essa nova forma de administrar a educação constitui-se num fazer coletivo, permanentemente em processo, processo que é mudança contínua e continuada, mudança que está baseada nos paradigmas emergentes da nova sociedade do conhecimento, os quais, por sua vez, fundamentam a concepção de qualidade na educação e definem, também, a finalidade da escola. (Bordignon et. al. 2004, p. 147)

Pode até parecer inovador demais para uma sociedade que engatinha ainda para a plena democracia, mas é este o modelo de escola que precisa estar consolidado no século XXI, baseado numa mudança de comportamentos e aperfeiçoamento de sua cultura, que além de se servir para discutir saberes teórico leve os educandos a prática efetiva dos conhecimentos adquiridos.

\section{DESAFIOS DA GESTÃO PARTICIPATIVA}

$\mathrm{Na}$ atualidade a gestão participativa tem sido mais ampliada após ser provocada na LDB, por meio do seu Art. $3^{\circ}$, inciso VIII, que trata da gestão nas escolas, mas a realidade ainda é bem diferente do que sugere a legislação. Isso é provocado por um entendimento de que a autonomia das escolas, em especial as municipais e estaduais estão subordinadas a gerência das Secretarias de Educação.

A autonomia da escola também é uma das nuances abordadas pela LDB, e não depende dor órgãos municipais ou estaduais de educação, a aplicação de muitas das decisões que são apenas de interesse da escola, por isso que é um entrave para algumas instituições de ensino a aplicação de uma gestão participativa eficiente, pois a escola acaba sendo vinculada aos interesses de um grupo político que esteja em evidência. Fica aqui uma reflexão sobre a importância de uma escola com independência nas palavras de Neves (1995) "A autonomia é a possibilidade e a capacidade da escola elaborar e programar um projeto político-pedagógico que seja relevante à comunidade e à sociedade a que serve.” Esta capacidade deve servir não apenas para este fim, mas também para o administrativo, o financeiro, o pedagógico e o jurídico da escola.

Percebe-se que as dificuldades de aplicação de uma gestão participativa escolar, estão relacionadas com a falta de emancipação das instituições escolares, sendo influenciadas por um conjunto de exigências, ou arcabouços pedagógicos definidos pelo órgão de educação a que estar subordinado.

\section{CONSIDERAÇÕES FINAIS}

A democracia exerce na sociedade contemporânea um importante papel como vinculadora de idéias que se baseiam na participação e produção social, cuja publicidade é feita pela escola através do processo de ensino-aprendizagem. 
A escola se torna uma difusora dos princípios democráticos, que contemplam a participação popular, a mesma escola que tem em sua estrutura pedagógica e administrativa que se adaptar aos princípios de democracia, com a abertura para o envolvimento da sociedade durante as escolhas e atividades que são necessárias ao desenvolvimento da escola.

$\mathrm{Na}$ escola é que se pode verificar como a gestão está sendo exercida e que a função desta atividade é de organizar e sistematizar as atividades a fim de que os objetivos propostos sejam atendidos, resultando em aproveitamento social para a comunidade escolar. A gestão escolar precisa despertar para a escolha de um modelo que procure aproximar a comunidade da escola por meio da representatividade social.

Não basta apenas que a os modelos de gestão forcem a uma participação social, mas é preciso que os gestores escolares fortaleçam as dimensões da gestão participativa através da descentralização do poder e envolvimento da comunidade escolar, além de uma definição de como acontecerá essa participação. Para alcançar estas metas as escolas devem abraçar a autonomia e construir a emancipação necessária para sozinha deliberar sobre suas necessidades e limitações sem a interferência direta de órgãos colegiados de educação.

Logo, a gestão participativa nas escolas ainda é sensível, embora as teorias apontem que este modelo é acertado diante de uma sociedade que tem comportamentos democráticos como o Brasil e que tem exigido o acompanhamento dos serviços oferecidos pelas organizações sociais, como é o caso do ensino público.

\section{REFERÊNCIAS}

BORDIGNON, Genuíno e GRACINDO, Regina Vinhaes. Gestão da educação: município e escola. IN: FERREIRA, N. S. e AGUIAR, M. A. (Orgs.). Gestão da Educação: impasses, perspectivas e compromissos. São Paulo: Cortez, 2004.

BRASIL. Leis de Diretrizes e Bases da Educação. Aracaju: Sintese, 2007.

BRASIL. Ministério da Educação. Secretaria de Educação Básica. Programa Nacional de Fortalecimento dos Conselhos Escolares. Gestão da educação escolar. Brasília: $\mathrm{UnB} / \mathrm{CEAD}, 2004$.

FARIA, José Henrique de. Gestão Participativa: relação de poder e de trabalho nas organizações. São Paulo: Atlas, 2009.

LIMA, Licínio C. Construindo Modelos de Gestão Escolar. Lisboa: Instituto de Inovação Educacional, 1999.

LOPES, J. Uma introdução ao Estudo da Escola do Terceiro Milênio: a escola contingencial. In: Revista de Administração Educacional. Recife, v.1, nº 1, p.1-88, 1997. 
MILL, John Stuart. O Governo Representativo. São Paulo: editora escola, 2006.

NEVES, Carmem Moreira de Castro. Autonomia da escola pública: um enfoque operacional. In: VEIGA, Ilma Passos A. (org.). O Projeto Político-Pedagógico e a organização do trabalho da escola. Campinas: Papirus, 1995.

WITTMANN, L.C. Fundamentos da Gestão Democrática nas Escolas. In: Brasil. Ministério da Educação. Seminário Internacional: Gestão Democrática da Educação e Pedagogias Participativas - caderno de textos. Brasília: D.F, 2006. 